\title{
THE ABSORPTION AND EXCRETION OF RADIOCOPPER IN HEPATO-LENTICULAR DEGENERATION (WILSON'S DISEASE)
}

\author{
BY \\ W. B. MATTHEWS \\ From King's College Hospital, London
}

Hepato-lenticular degeneration stands almost alone among diseases of the nervous system in the wealth of biochemical information available, but there is, as yet, no generally acceptable explanation of the underlying disorder of metabolism. Any such theory must take into account all the biochemical abnormalities so far discovered. The disease is an inborn error of metabolism transmitted by recessive inheritance (Bearn, 1953). Copper accumulates in the liver and brain (Cumings, 1948) and cornea (Brand and Takats, 1951) and, paradoxically, the urinary excretion of copper is greatly increased (Mandelbrote, Stanier, Thompson, and Thruston, 1948). This excretion is more than offset by diminished elimination in the faeces, resulting in a strongly positive copper balance (Zimdahl, Hyman, and Cook, 1953). The normal specific copper plasma protein, caeruloplasmin, is largely deficient (Scheinberg and Gitlin, 1952). The results of treatment with dimercaprol (B.A.L.) reported by Denny-Brown and Porter (1951) leave little doubt that the neurological symptoms at least are due to copper poisoning. In addition to these abnormalities of copper metabolism the disease is characterized by renal amino-aciduria (Uzman and Denny-Brown, 1948) and by the presence of specific peptides in the urine (Uzman and Hood, 1952 ; Uzman, 1953).

Opinion is divided as to whether the accumulation of copper in the body is of primary importance or is merely secondary to some other metabolic disorder which is itself responsible for the lesions in the liver and brain. It is therefore important to establish whether this accumulation is due to over-absorption of the metal or to undue retention in the tissues. Zimdahl and others (1953) claimed to have demonstrated over-absorption but their results could equally be explained by failure of the normal route of excretion into the intestine. Their method of copper balance on a varying copper intake does not permit distinction between faecal copper that has passed through unabsorbed and that which has been excreted into the intestine. To do this it is necessary to follow the fate of a single dose, which may be attempted either by giving a loading dose to a patient already established on a constant copper intake, a difficult task, or else, as suggested by Matthews, Milne, and Bell (1952), by using radioactive copper, ${ }^{64} \mathrm{Cu}$.

There are numerous difficulties in such an investigation. The isotope can only be obtained as a small proportion of inactive carrier and has a short halflife of 12.8 hours. Other limiting factors are the potential toxicity of copper, the possible effects of radiation, and the small number of patients with this uncommon disease available for investigation.

\section{Clinical Material}

Two patients were investigated. Both were young adult males with the more chronic "pseudosclerotic" form of the disease, and showed the characteristic amino-aciduria and increased urinary copper. Serum copper levels were within or below the normal range. Hepatic disease, as estimated clinically and by liver function tests, was not obvious in either case. Case 1 was almost symptom free following repeated courses of B.A.L. and continuous glycine by mouth, but Case 2 was severely incapacitated. Three adult male volunteers with unrelated chronic neurological disease and one normal subject acted as controls. It was not thought that the doses of copper employed would prove toxic to the patients as the lower dose was roughly equivalent to one day's urinary output on B.A.L. and very much larger quantities had repeatedly been removed from Case 1 by courses of treatment. In fact, no toxic effects attributable to copper were observed.

\section{Methods}

Radioactive copper, ${ }^{64} \mathrm{Cu}$, was received from the Radiochemical Centre, Amersham, as a solution of copper sulphate. A known fraction was removed as a standard and the remainder given to the subject by mouth in about 
$200 \mathrm{ml}$. of water three hours after a light breakfast. Two series of experiments were carried out. In a preliminary trial $1.2 \mathrm{mg}$. of labelled copper with an approximate activity of $25: \mathrm{C}$ was given to the two patients and to two controls. The general shape of the plasma curve was investigated and urine was collected as passed in the first few hours following ingestion, but the activity was not sufficient for elimination in the faeces to be followed for long enough with the apparatus available. In the second series $4.95 \mathrm{mg}$. of labelled copper with an approximate activity of $125 \mu \mathrm{C}$ was given to the two patients and to two different controls, together with a carmine marker. Plasma levels were estimated at times suggested by the results of the first experiment and 24-hour specimens of urine and faeces were collected.

Blood was heparinized and centrifuged and the activity of the plasma was counted directly in a liquid counter (M.R.C. type M6M). Urine was also counted directly. Specimens of faeces were thoroughly mixed and approximately $5 \mathrm{~g}$. portions were digested by the method of Eden and Green (1940), made to volume, and counted in the liquid counter. The short half-life of the isotope necessitated rapid preparation of the specimens. It proved possible to follow the excretion in the urine for 48 hours and in the faeces for four days. The dose of radiation was considerably less than that authorized as safe by the Medical Research Council.

\section{Results}

Plasma.-Absorption curves with a peak at one to two hours were obtained (Figs. 1 and 2). The
Fig. 2.-Copper absorption curves : results following ingestion of $4.95 \mathrm{mg}$. of copper labelled with ${ }^{\circ} \mathrm{Cu}$. Broken line, controls ; solid line, patients with Wilson's disease.

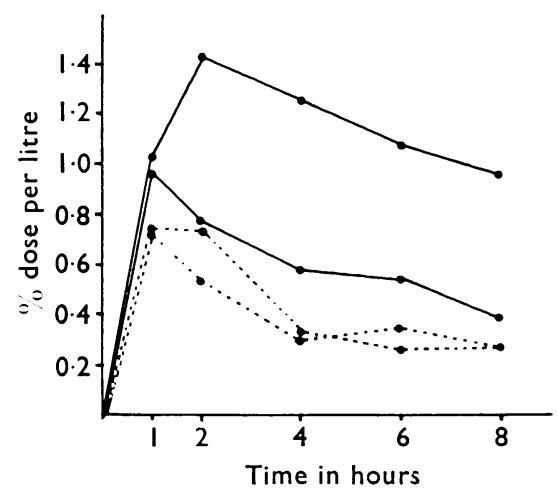

maximum levels following $1.2 \mathrm{mg}$. of copper were 1.04 and $1.13 \%$ of the total dose per litre of plasma in the controls and 1.09 and $1.19 \%$ in the patients. In the controls following $4.95 \mathrm{mg}$. of copper a smaller percentage appeared in the plasma, maximum levels being 0.72 and $0.75 \%$ of the total dose per litre as opposed to 0.96 and $1.44 \%$ in the patients. Once the peak had been reached every point on the curves in the patients was higher than the corresponding point in the controls. Following the

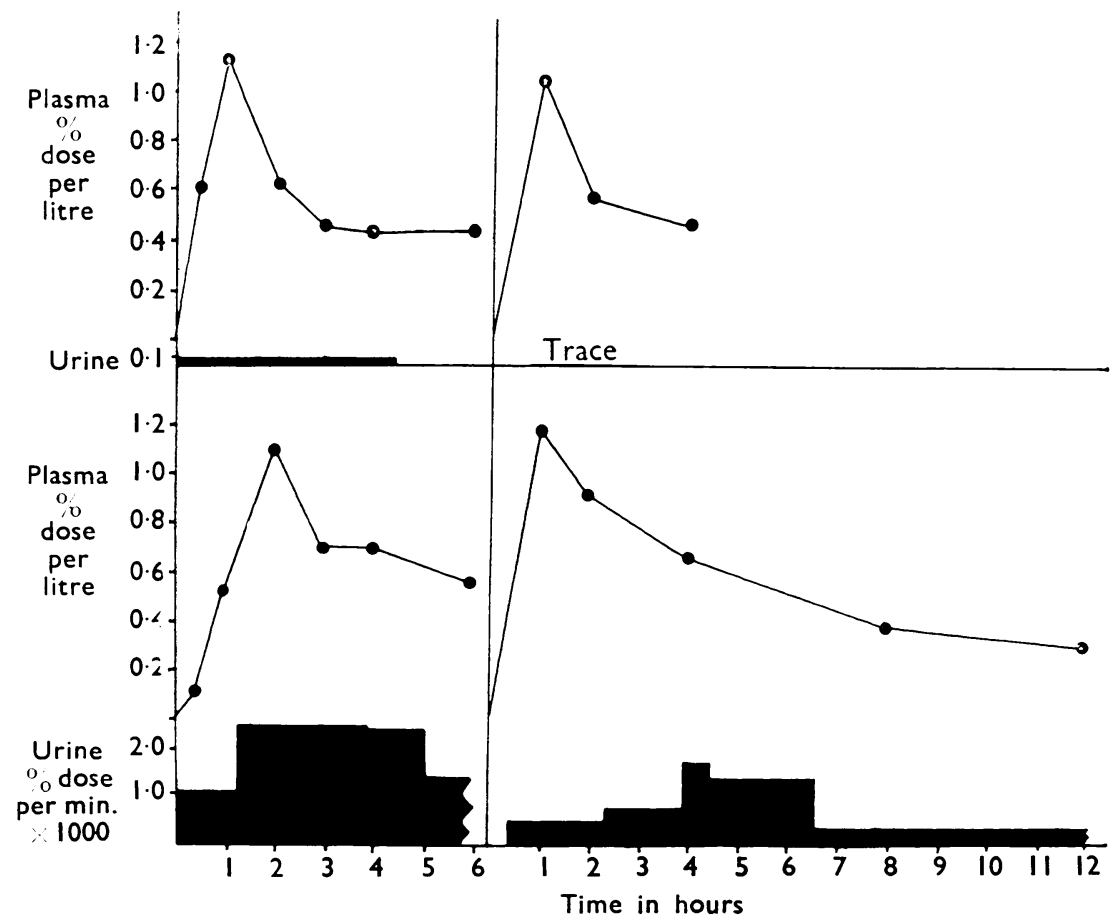

Fig. 1.-Copper absorption curves and urinary excretion: results following ingestion of $1.2 \mathrm{mg}$. of copper labelled with ${ }^{64} \mathrm{Cu}$. Two controls above; two patients with Wilson's disease below. 
larger dose considerably higher plasma levels were found in Case 2 who had developed the disease at an earlier age and in a more severe form than Case 1.

These figures do not, of course, necessarily indicate parallel changes in the total plasma copper level, and no attempt was made to estimate this concurrently. The highest level of labelled copper found in the plasma was approximately equivalent to $7 \mu \mathrm{g}$. of copper per $100 \mathrm{ml}$., and changes of this order could not be determined accurately by chemical means.

Faeces.-The recovery of labelled copper in the faeces after the ingestion of $4.95 \mathrm{mg}$. is shown in Fig. 3. Collection of specimens was satisfactory in

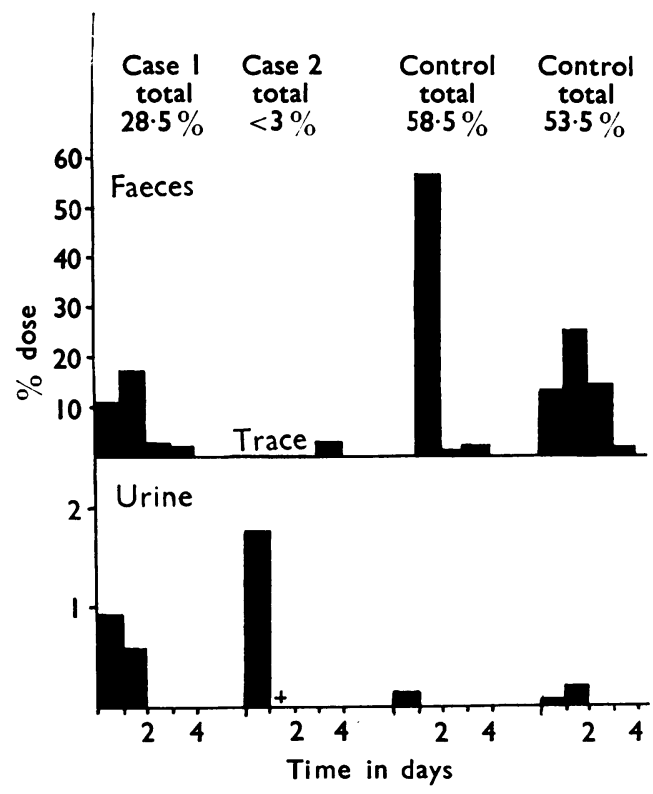

Fig. 3.-Faecal and urinary recovery of oral copper : results following ingestion of $4.95 \mathrm{mg}$. of copper labelled with ${ }^{64} \mathrm{Cu}$.

Case 1 and in both controls but proved difficult in Case 2 in whom some degree of faecal retention could not be excluded. In view of the high plasma curve, severe disease, and high urinary excretion in this patient, and also the recovery of some radiocopper on the first day it is possible that the figure of less than $3 \%$ recovery in four days may not be misleading and the result is included. In Case 1, $28.5 \%$ of the dose was recovered and in the controls 58.5 and $53.5 \%$. The recovery of only small quantities on the fourth day shows that the greater part of the dose remaining unabsorbed had been recovered.
Urine.-A very striking difference in urinary excretion was found both in the 24-hour specimens (Fig. 3) and in the fractionated specimens collected during the preliminary experiment. It can be seen from Fig. 1 that this increased rate of excretion in the patients was present when plasma levels were almost identical with those of the controls at the peak of the absorption curves and continued after the peak had been passed.

\section{Discussion}

Normal Copper Metabolism.-Knowledge of copper absorption in man is scanty, partly because it is not possible to detect any rise in plasma copper by chemical means even after massive oral doses (van Ravesteyn, 1944 ; Gubler, Lahey, Cartwright, and Wintrobe, 1953). The doses of copper employed in the present investigation cannot be described as physiological in that such amounts would not normally be encountered in a single meal. They are, however, much more closely related to the normal minimum daily requirement of $2 \mathrm{mg}$. (Cartwright, 1950) than those used in previous investigations with unlabelled copper. Schubert and Riezler (1947) reported the only similar investigation in man using ${ }^{64} \mathrm{Cu}$, but did not follow plasma levels closely in the few hours after ingestion or report individual results in detail. It is difficult to compare their results with the present figures but levels appear to have been of the same order. The results reported here suggest that a rapid initial absorption takes place and that the newly absorbed copper reaches equilibrium with pre-existing plasma copper after about four hours.

The very small quantities recovered in the urine confirm that this method of excretion is of little importance in normal copper metabolism (van Ravesteyn, 1944). Recovery of 58.5 and $53.5 \%$ of the dose in the faeces does not agree very well with the results of Schubert, Maurer, and Riezler (1948) who recovered $91 \%$ of $3.79 \mathrm{mg}$. of labelled copper in five days. The latter figure would imply that most of the normal faecal copper is derived directly from unabsorbed ingested copper. Zimdahl and others (1953) found that when copper absorption was largely prevented by means of an ion exchange resin the faecal copper was greatly in excess of the intake over a 12-day period, presumably due to the excretion of copper from body stores. In view of this large contribution of excreted copper to the total faecal copper the present figures appear reasonable. The quantity recovered undoubtedly contained a proportion of re-excreted copper but this could not be large for van Ravesteyn (1944), Schubert and 
others (1948), and Marcus and Rotblat (1950) all reported a considerable delay in the intestinal excretion of more than a small proportion of copper given parenterally. Under the conditions of this test, therefore, approximately half the ingested dose was probably absorbed.

Copper Metabolism in Wilson's Disease.-Uzman (1953) has recently advanced the theory that the initial metabolic disorder in hepato-lenticular degeneration is one of proteolytic activity leading to the accumulation in the tissues of the specific peptides that he has identified in the urine. The peptides readily combine with copper and would lead to a secondary accumulation of copper in the tissues. He has suggested that the peptides, either free or combined with copper, compete with aminoacids for reabsorption by the renal tubules, thus producing both amino-aciduria and the appearance of copper-peptide complexes in the urine. He has been able to show that most of the urinary copper in Wilson's disease is actually present as such complexes. On this theory the positive copper balance would presumably be due to undue retention of copper in the tissues and not to over-absorption.

An alternative theory is that the lack of some hypothetical regulating activity normally exerted by the copper plasma protein, caeruloplasmin, which is deficient in this disease, leads to chronic overabsorption of copper from the intestine. Hepatic and cerebral damage, abnormal peptide metabolism, and renal amino-aciduria would then all be attributable to copper poisoning. There is considerable evidence that the cerebral lesions are to a large extent reversible by treatment with B.A.L., and renal amino-aciduria has recently been shown to accompany lead poisoning (Wilson, Thomson, and Dent, 1953). On either theory excessive excretion of copper in the urine might only be a late result of chronic accumulation in the body, and the discovery of amino-aciduria without excessive urinary copper in asymptomatic sibs of known cases of the disease (Uzman and Hood, 1952) cannot be used as an argument for the secondary nature of the disorder of copper metabolism.

The present investigation was designed to establish whether over-absorption of copper occurs in Wilson's disease or not. Unfortunately the small number of cases available did not allow conclusive results to be obtained. A considerably larger proportion of the ingested dose was, however, recovered from the faeces of the controls than of the patients and this finding is in favour of overabsorption, but requires confirmation in a larger series of patients.
No striking difference was found between plasma levels in the patients and in the controls, although rather higher levels were consistently found in the former. The plasma levels are the result of a number of variables including rate of absorption, rate of entry into the tissues, and rate of urinary excretion, and slight differences may therefore conceal considerable but opposing disturbances of these factors. The plasma levels therefore provide no evidence of over-absorption, but also do not suggest unduly rapid clearance of the plasma due to excessive uptake of copper by the tissues.

A very much larger proportion of the ingested dose was excreted in the urine by the patients than by the controls in spite of very similar plasma levels (Figs. 1 and 3). The problem of urinary excretion of copper was fully reviewed by Matthews and others (1952) who suggested that the plasma contains copper bound in an abnormal form able to pass the glomeruli, and the present investigation provides strong supporting evidence for this theory. Although greatly in excess of normal the actual quantities of copper recovered in the urine were very small. Case 1, after ingesting $4.95 \mathrm{mg}$. of copper, a quantity in excess of the normal daily intake, passed only $47 \mu \mathrm{g}$. of labelled copper in 24 hours. This patient on a normal diet habitually excreted approximately $500 \mu \mathrm{g}$. in the urine daily. The abnormally combined fraction of plasma copper available for renal excretion cannot, therefore, be confined to newly absorbed copper in transport. It is clear that the greater part of the urinary copper in Wilson's disease is not directly derived from the alimentary intake.*

\section{Conclusion}

The use of ${ }^{64} \mathrm{Cu}$, despite certain disadvantages, appears to be a valuable method of investigating normal and abnormal copper metabolism. The results of this investigation are in favour of overabsorption of copper in hepato-lenticular degeneration and therefore support the theory of a primary disorder of copper metabolism. Further evidence was produced that copper exists in an abnormal form in the plasma in this disease. Ignorance of the factors responsible for the normal regulation of

* Since this paper was submitted for publication, Bearn and Kunkel (1954, Proc. Soc. exp. biol. Med., 85, 44), using ${ }^{64} \mathrm{Cu}$, have shown that newly absorbed coprer is attached to the albumin fraction of the plasma proteins. In the normal subject it is then rapidly transferred to caeruloplasmin, but in Wilson's disease this does not occur, presumably because of the deficiency of this protein. These authors also confirm that following oral administration of ${ }^{64} \mathrm{Cu}$ a higher proportion appears in the urine in patients with Wilson's disease than in normal subjects. Following intravenous injection excretion in the faeces was lower than normal. Their results are not reported in detail and the recovery of ${ }^{64} \mathrm{Cu}$ from the faeces after oral administration was apparently not attempted. 
copper absorption forms one of the obstacles to a fuller understanding of the pathogenesis of Wilson's disease, and experiments with radiocopper designed to elucidate this problem would probably yield valuable results.

\section{Summary}

Copper sulphate labelled with ${ }^{64} \mathrm{Cu}$ was given by mouth to two patients with Wilson's disease and to normal controls.

A larger proportion of the ingested dose was recovered in the faeces of the controls than in the patients.

The patients passed a much larger proportion of the dose in the urine than did the controls.

Plasma levels were not strikingly different in the patients and controls but slightly higher values were found in the former.

It is concluded that there was evidence of overabsorption of copper by the patients and that copper existed in an abnormal form in the plasma.

I wish to thank Dr. S. Nevin for permission to investigate patients under his care and Dr. W. Ritchie Russell for referring Case 2. I also wish to thank Professor C. H. Gray for encouragement and the Research Committee of King's College Hospital for a grant for expenses. The work could not have been done without the scrupulous collection of specimens by the nursing staff of Fisk ward.

\section{REFERENCES}

Bearn, A. G. (1953). Amer. J. Med., 15, 442.

Brand, I., and Takats, I. (1951). v. Graefes. Arch. Ophthal., 151, 391. Cartwright, G. E. (1950). In A Symposium on Copper Metabolism. Ed. W. D. McElroy and B. Glass, pp. 274-314. Johns Hopkıns Press, Baltimore.

Cumings, J. N. (1948). Brain, 71, 410.

Denny-Brown, D., and Porter, H. (1951). New Engl. J. Med. 245 917.

Eden, A., and Green, H. H. (1940). Biochem. J., 34, 1202.

Gubler, C. J., Lahey, M. E., Cartwright, G. E., and Wintrobe, M. M. (1953). J. clin. Inve:t., 32, 405.

Mandelbrote, B. M., Stanier, M. W., Thompson, R. H. S., and Thruston, M. N. (1948). Brain, 71, 212.

Marcus, R., and Rotblat, J. (1950). Brit. J. Radiol., 23, 541 is.

Matthews, W. B., Milne, M. D., and Bell, M. (1952). Quart. J. Med. $21,425$.

Ravesteyn, A. H. van (1944). Acta med. scand., 118, 163.

Scheinberg, I. H., and Gitlin, D. (1952). Science, 116, 484.

Schubert, G., Maurer, W., and Riezler, W. (1948). Z. ges. inn. Med., 3, 170.

- -, and Riezler, W. (1947). Klin. Wschr., 24, 304.

Uzman, L. L. (1953). Amer. J. med. Sci. 226645.

, and Denny-Brown, D. (1948). Ibid., 215, 599.

-, and Hood, B. (1952). Jbid., 223, 392. Wilson, V. K., Thomson, M. L., and Dent, C. E. (1953). Lancet,

Zimdahi, W. T., Hyman, I., and Cook, E. D. (1953). Neurolog!", 